\title{
Research on Risk Management Strategy in Purchase-Order Financing
}

\author{
Business of Bank \\ Li Zhang, Zhiyu An * \\ School of Economics and Management, Nanjing University of Science and Technology, \\ China \\ *Corresponding author: Zhiyu An, Associate Professor,zhiyu_ann@163.com
}

\begin{abstract}
This paper studies the strategies of purchase-order financing business for banks based on the behavior of the small and medium enterprise suppliers and the core manufacturers. The studies have shown that the main risk of order financing includes the credit risk of the buyer and the sellers. Banks should not only strengthen supervision, but also use the target incentive policy and risk management decisions to avoid moral hazard and adverse selection.
\end{abstract}

Key words: purchase-order financing; principal-agent theory; risk management

\section{Introduction}

The seller's business needs a lot of liquidity to purchase to recover the sales price. However, it is difficult for the small seller's business in accordance with the traditional way to get loans from banks ${ }^{1}$. In view of this phenomenon, the bank launch the order financing business to expand the size of the loan and open up new sources of profit.

The current development situation of order financing in China is not ideal. For risk factors and asymmetric information, the bank issued on the orders of the party and other aspects of strict restrictions in order to avoid the risk of financing, resulting in a large number of small and medium-sized enterprise financing orders can't be achieved. Therefore, there is a certain significance to the research of the risk management and control of order financing. The factors index, mainly using quantitative model and game theory, the risk management decision model of construction bank order financing business is expected to provide a theoretical basis for banks to make risk management decisions in the development of such services, and proposed some useful suggestion for the development of the financing order ${ }^{2}$.

\section{The Order financing model with the default risk}

\subsection{Model assumptions and symbolic meanings}

In this paper, based on the theory of game theory ${ }^{3-5}$, the following assumptions are made: the buyer, the seller are rational and the risk neutral. The banks are rational, risk averse. So the factors that will affect the return of the bank, the buyer and the seller can be expressed as the 
variables. The main symbols and their meanings are as follows: $r$ : bank loan interest rate. $r_{0}$ : bank deposit rates. $r>r_{0} \cdot r_{1}$ : the proceeds from the production of the seller's enterprise with the loan funds. $A$ : the amount of the order financing is also approximately equal to the buyer's purchase cost to the seller. $w$ : loan pledge rate. $b$ : the positive benefits when the seller's enterprise does not work. $C$ : the transaction costs for banks to obtain cost and transaction information of small and medium enterprises. $\theta$ : the discount rate when the seller default to complete the order but the buyer can cash in bank loans. $M$ : if the seller is not hardworking and the risk of moral hazard, it will suffer the loss quantification of $\mathrm{M}$. The seller's small and medium enterprises may be bankrupt. $P_{b}$ : the probability of buyer performs well under the natural state. $P_{S}$ : the probability of the seller effort under the natural state. $Y:$ the buyer gives the bank guarantee compensation. $R$ : buyer's final sales revenue. $N$ : if the buyer does not perform the contract, the negative impact is $\mathrm{N}$. $C_{1}$ : the buyer's business is as a guarantee after the bank to obtain information about the SME financing, information acquisition costs $C_{1}<C . X$ : the opportunity cost of the buyer or the sunk cost that have signed sales contract breach. $I$ : the positive benefits can be $I$ when buyer enterprise is in the choice of non-performance.

\subsection{Solution of the model}

\subsubsection{The model only considering seller's risk}

When the buyer's credit conditions are in good condition such as the state-owned enterprises, the government, the buyer's default risk can be ignored, only considering the seller's credit risk $^{6}$. The gain matrix is shown in Table 1.

(1) Static game of complete information.

The seller's business and the bank are fully aware of each other's benefits. If the bank does not loan, the seller's repayment is 0 whether or not proceeds the business ${ }^{7}$. When bank loans, the seller's efforts are $\left.A w\left(r_{1}-r\right)\right)$, the seller does not work hard so the return are

Table 1 - Gain matrix of the model only considering seller's risk

\begin{tabular}{|l|l|c|c|}
\hline \multirow{2}{*}{} & \multicolumn{3}{|c|}{ Small and medium sized enterprises } \\
\cline { 2 - 4 } & & Obey the rule & Break the rule \\
\hline \multirow{3}{*}{ Bank } & loan & $\left(\left(r-r_{0}\right) A_{W}-C, A_{W}\left(r_{1}-r\right)\right)$ & $\left(-A_{W}\left(1+r_{0}\right)-C, A_{W}(1+r)+b-M\right.$ \\
\cline { 2 - 4 } & No loan & $\left(-A_{W r_{0}}, 0\right)$ & $(0,0)$ \\
\hline
\end{tabular}

$[A w(1+r)+b-M],(b-M>0)$ the seller will make no effort to make decisions, therefore, 
the seller does not repay the proceeds of a large enterprise. Therefore, according to the principle of maximizing the interests of individuals, there is a dominant strategy - no repayment small and medium enterprises whether or not the bank loans. At this point, the bank can only choose not to loan to minimize the loss of their own. So at this time of the Nash equilibrium is (no loans, no repayment), the two sides benefit from $(0,0)$. But there is clearly a better strategy than the current balance of Nash, which in this game (loans, repayment). So at this time there is a Pareto improvement, bank can change the current through the conditions of the Nash equilibrium to achieve Pareto efficiency. In the long run, if the seller's business continues, the game is repeated games. If the seller enterprise does not repay at the first time, the bank in a game will not loan, then the game is over. If the enterprise repays, the bank can predict that the company still repayment next time, the bank will loan.

(2) Incomplete information game.

In fact, the bank and the seller's business did not reach the optimal loan policy, because there is information asymmetry between banks and the seller. The probability of the seller's efforts is $P_{s}$. The probability of default is $\left(1-P_{s}\right)$ due to the lack of repayment ability or the lack of effort by the seller enterprises. The expected return of the bank when the bank is lending:

$$
E(\text { loan })=P_{s}\left[\left(r-r_{0}\right) A W-C\right]+\left(1-P_{s}\right)\left[-A_{W}\left(1+r_{0}\right)-C\right]
$$

When the bank does not loan, the bank's expected return is:

$$
E(\text { noloan })=-P_{s} A w r_{0}+\left(1-P_{s}\right) * 0=-A P_{s} W r_{0}
$$

And $E($ loan $)=E($ noloan $)$

So

$$
P_{s}=\left[C+A w\left(1+r_{0}\right)\right] /\left[A w r+A W\left(1+r_{0}\right)\right]
$$

$P_{s}$ the critical point of bank offer loan and no loan. So, if $P_{s}>\left[C+A_{W}\left(1+r_{0}\right)\right] /\left[A W r+A_{W}\left(1+r_{0}\right)\right]$, the bank will loan, the equilibrium at this time is (loan, effort). Once the business problems occur, it will lose the ability to repay. In conclusion, in the game between small and medium-sized enterprises and banks, as the bank information at a disadvantage and small and medium-sized enterprises lack strong constraints, business instability, credit level is low, it is more difficult to obtain loans. Even if the bank loans, loan interest rates are generally higher.

\subsubsection{The model considering seller and the buyer risk}

When the buyer is not a state-owned enterprise, the government and others, the model should consider the buyer's default risk and the seller's credit risk at the same time ${ }^{8}$. At this time, the risk of the bank is mainly the moral hazard of the seller and the adverse selection of the buyer's enterprise. The gain matrix of the model considering seller's and the buyer's risk is shown in Table 2. 
Table 2 - Gain matrix of the model considering seller's and the buyer's risk

\begin{tabular}{|c|c|c|c|}
\hline \multicolumn{2}{|c|}{ bank loans } & \multicolumn{2}{|l|}{ Buyer enterprise } \\
\hline & & Performance & Not Performance \\
\hline \multirow{6}{*}{$\begin{array}{l}\text { Seller } \\
\text { enterprise }\end{array}$} & \multirow{3}{*}{$\begin{array}{l}\text { Obey the } \\
\text { rule }\end{array}$} & $\left(r-r_{0}\right) A_{W}-C_{1}$ & $\operatorname{Min}\left\{A w r_{1} \theta, A W r\right\}-A W r_{0}-C_{1}$ \\
\hline & & $R-A$ & $I-X-N$ \\
\hline & & $\left(r_{1}-r\right) A W$ & $A w r_{1} \theta-A w r$ \\
\hline & \multirow{3}{*}{$\begin{array}{l}\text { Break the } \\
\text { rule }\end{array}$} & $-\left(1+r_{0}\right) A_{W}-C_{1}+Y$ & $-\left(1+r_{0}\right) A W-C_{1}$ \\
\hline & & $-Y-X$ & $I-X-N$ \\
\hline & & $(1+r) A W+b-M$ & $(1+r) A W+b-M$ \\
\hline
\end{tabular}

(1) Static game of complete information.

In one game, the seller and the buyer default loss will not have a direct impact, $M=0, N=0$. At this time, if the seller does not work, then the benefit that buyer chooses not to perform more than the benefit that buyer choose to perform, $I-X>Y-X$, so the buyer chooses not to fulfill the contract. If the seller enterprise perform, the performance gains is $R-A+X-I$, in which $R-A>0$, there will be a beginning of the order contract, of which $\mathrm{I}$ is according to the market situation and the actual specific changes. Because of $I>X$, the buyer will consider the breach of contract, the buyer performance benefits minus benefits from non-performance gains $R-A+X-I>0$, so the buyer has the advantage strategy in repayment, the buyer will choose not to perform the known circumstances. When $A_{W}\left(R_{1} \theta-2 r-1\right)-b>0$, the Nash equilibrium is (efforts, no performance). When $A_{W}\left(R_{1} \theta-2 r-1\right)-b<0$, the Nash equilibrium is (no effort, no performance). With complete information, the bank can be predicted by the seller and the buyer's choice, so when the $A w\left(r_{1} \theta-2 r-1\right)-b>0$, if $\theta$ change with the market factors very small, so that $\operatorname{Min}\left\{A w r_{1}, A w r\right\}-A w r_{0}-C_{1}<0$, then the bank will give orders financing business.

When $A_{W}\left(r_{1} \theta-2 r-1\right)-b<0$, the bank will choose not to loan, the Nash equilibrium is (not loans, not hard, not performance).

When the buyer's perform well, compare the seller's efforts to return $A_{W}\left(r_{1}-r\right)$ and the seller does not work hard to gain $A_{W}(1+r)+b-M$, if $M>b+A_{W}\left(1+2 r-r_{1}\right)$, the seller will choose to work hard. When the buyer does not perform the contract, compare the seller to return $A w r_{1} \theta-A w r$ and the seller does not return $A w(1+r)+b-M$, if 
$M>b+A_{W}\left(1+2 r-r_{1} \theta\right)$, the seller will choose to work hard.

Therefore, the seller will face the large enough punishment when the seller does not work hard, so there is a strict policy for the seller, that is to work hard. The buyer's enterprise can analyze the choice of the seller's enterprise, then it can only choose the strategy of maximizing its own interests in the seller's enterprise. Compared the return when buyer does not perform $R-A$ with the return performance gains of $I-X-N$ as long as $N>I-X+A-R$, namely the buyer's breach of contract will be large enough to punish, it will choose the performance, the existence of Nash equilibrium is (effort, performance). Under the complete information, the bank can predict the choice of the seller and the buyer (hard, performance). The bank will choose loans from the perspective of maximizing their interests. At this time of Nash equilibrium is (loan, efforts, performance) is Pareto effective.

(2) Incomplete information game.

At this point, the bank will determine whether to lend. There are four possible. In order to facilitate the research, we introduce a virtual game, virtual game has four kind of natural state, four combinations represent respectively the buyer and the seller, A1 (efforts, performance), A2 (no effort, breach of contract), A3 (no effort, performance), A4 (effort, breach of contract).

The performance probability is the probability of $P_{b}$, seller's efforts is Ps, then the bank knows the probability of the four state respectively for $P_{s} P_{b},\left(1-P_{s}\right)\left(1-P_{b}\right),\left(1-P_{s}\right) P_{b}, P_{s}\left(1-P_{b}\right)$.

$$
\begin{gathered}
E(\text { loan })=P_{s} P_{b}\left[A w\left(r-r_{0}\right)-C_{1}\right]+P_{b}\left(1-P_{s}\right)\left[-A w\left(1+r_{0}\right)-C_{1}+Y\right] \\
+\left(1-P_{b}\right) P_{s}\left[\min \left\{A w r_{1} \theta, A w r\right\}\right]-\left[A w r_{0}-C_{1}\right]+\left(1-P_{b}\right)\left(1-P_{s}\right)\left[-A w\left(1+r_{0}\right)-C_{1}\right] \\
=P_{b} P_{s}\left[\left(A w r-\min \left\{A w r_{1}, A w r\right\}\right]+P_{b} Y+P_{s}\left[\min \left\{A w r_{1} \theta, A w r\right\}+A w\right]-A w\left(1+r_{0}\right)-C_{1}\right. \\
E(\text { loan })=E(\text { noloan })
\end{gathered}
$$

It is known that when $P_{s}$ and $P_{b}$ obey the following conditions, the probability of the seller and the buyer have a variable, when the bank's expected return is greater than 0 , the bank will choose the loan. Under this condition the Pareto Nash equilibrium (loans, efforts, performance) can be obtained.

$$
P_{b} P_{s}\left[\left(A w r-\min \left\{A w r_{1}, A w r\right\}\right]+P_{b} Y+P_{s}\left[\min \left\{A_{w r} \theta, A w r\right\}+A w\right]>A w\left(1+r_{0}\right)+C_{1}\right.
$$

\section{Results and Discussion}

Through the analysis of the second models, when the seller and the buyer default penalties is large enough, it will greatly reduce the probability of default. So the establishment of comprehensive and rigorous order financing credit evaluation system, including the order of financing credit rating, punishment mechanism, is so useful so as to prevent the enterprise 
default.

\section{Conclusion}

In order to avoid the loss of the interests of the banks because of buyer's choice of default, the buyer should bear the cost of default or the opportunity cost of the original contract of production and sales, as well as the punishment from the supply chain and the bank. In addition to the study of their own, the bank should also investigate the macro environment and price trends in the enterprise and industry. When carrying out the order financing business, the bank should take the customer demand as the guidance, and innovate the business content through the customer market, and expand the income source. At the same time, bank could provide some additional value-added services to prevent the probability of default. To make the order financing business bigger, the bank must do in risk control on the basis of expanding the scope of application of order financing, give more financing for small and medium sized enterprises provide conditions but also to expand their profit space.

\section{References}

1. M.S. Yang, Research on Supply Chain Finance Pricing Problem under Random Demand and Permissible Delay in Payment, J. Procedia Computer Science. 17 (2013)245-257.

2. G.J.Hahn, H.Kuhn, Simultaneous investment, operations, and financial planning in supply chains: A value-based optimization approach, J. Int. J. Production Economics. 140 (2012)559-569.

3. Y.X. Li, Process-focused Risk Analysis and Management of Purchase-Order Financing under Logistic Financing Innovation, J. 2008 4th International Conference on Wireless Communications, Networking and Mobile Computing. [v.23], Dalian. 4 (2008)94469880.

4. Z. Qi, Purchase Order Financing Risk Evaluation Based on the Fuzzy Extension Analytic Hierarchy Process, J. Journal of Chongqing University of Technology (Social Science). 2 (2013) 36-39.

5. X.J.Xu, G.M.Sun, L.Yu, Analysis on loan pricing of small and micro enterprises based on order financing model money economy, J. Journal of Financial Economics. 8 (2013)135-137.

6. Q.Wang, Analysis on the risk analysis and management suggestions of commercial bank's order financing products, J. Modern economic information. 19(2014)355-362.

7. A.M.Deng, J.Xiong, F.Zhang, Order Financing Risk Pre-warning Model based on BP Network, J. Journal of Intelligence. 11 (2010) 23-28.

8. L. Pei. Research on financing mode and risk of order processing trade enterprises, J. China Business \& Trade. 16(2012)167-168. 